ORIGINAL ARTICLE

\title{
Frequency of Causes of Space Occupying Lesions of Brain in Patients admitted in Neurosurgery over A Period of One Year
}

\author{
ABDUL RAZAQUE MARI ${ }^{1}$, MUZAMIL DILBER ${ }^{2}$, FAHMIDA ARAB MALLAH ${ }^{3}$, MUHAMMAD ALI JAMALI ${ }^{4}$, SHAMS RAZA \\ BROHI ${ }^{5}$, MUHAMMAD ASLAM SHAIKH ${ }^{6}$ \\ ${ }^{1}$ Associate Professor and Chairman, Neurosurgery, Peoples University of Medical and Health Sciences, for Women Shaheed Benazirabad \\ ${ }^{2,3,4}$ Assistant Professor, Neurosurgery, Peoples University of Medical and Health Sciences, for Women Shaheed Benazirabad \\ ${ }^{5}$ Professor, Neurosurgery, Peoples University of Medical and Health Sciences, for Women Shaheed Benazirabad \\ ${ }^{6}$ Associate Professor, Neurosurgery, SMBBMU Larkana \\ Correspondence to: Dr. Abdul Razzaque Mari, Email: razakmari@yahoo.com
}

\begin{abstract}
Objective: To determine the frequency of causes of space occupying lesions of brain in patients admitted in Neurosurgery ward PUMHS Nawabshah over a period of one year

Methodology: This descriptive case-series study took place at department of Neurosurgery of Peoples University of Medical and Health Sciences, for Women Shaheed Benazirabad. Study duration was one year from July 2019 to June 2020. All the patients with space-occupying lesion of brain either of gender were enrolled in this study. All study subjects were assessed for the causes of space-occupying lesion. Data was collected vis study proforma and analysis of the data was done by using SPSS version 20.

Results: A total of 80 patients were selected, their mean age was 31.76 years and females were in majority $66 \%$, with female to male ratio of 1.96:1. Glioma was found in $23 \%$ cases which was highest among all type of lesion followed by abscess $10 \%$. Supratentorial was observed in $73 \%$ patients which was highest among all site of lesion followed by third ventricular \& Infratentorial $10 \%$ each.

Conclusion: The increased prevalence of infectious lesions can be linked to our population's low socioeconomic level and inadequate hygienic conditions. The rate of metastasis was found to be lower than previously reported. This might be attributed to cases not being referred following a metastatic lesion has been diagnosed. For early detection of brain tumours, advanced diagnostic equipment such as CT scans and MRI are desirable.
\end{abstract}

Keywords: SOL, Central Nervous System, Metastases

\section{INTRODUCTION}

Abscesses or tumours present within the skull or cranium are classified as intracranial space occupying lesions. In other two vessels, three forms of damage can occur: embolism, thrombosis, and injury-related damage. Lesions that take up a lot of space obstruct circulation, either indirectly or directly. Circulatory failure is the primary cause of functional loss. It is crucial to note that a physiological function loss that may be recovered comes before the unrecoverable destruction and softening. As a result, it's essential to differentiate the depression from loss of function. Around 45 million Americans suffer from chronic headaches, with at least $50 \%$ of them experiencing severe and sometimes debilitating symptoms. Headache discomfort accounts for nearly 8 million doctor visits each year. ${ }^{1,2}$ Headache is among the most frequent neurological referral presentations, so there is much concern about how serious this symptom can be. ${ }^{3}$ A research was undertaken to determine the incidence of incidental findings on brain MRI. The results showed that $15.1 \%$ of cases needed no referral, $1.8 \%$ of cases needed routine referrals, $1.15 \%$ of cases were urgent referral, and $0.5 \%$ of cases were immediate referrals. Two established primary brain tumours (and a likely yet undetermined third) were discovered among individuals classified for urgent referral, indicating an incidence of minimum $0.2 \%{ }^{4}$ Another research conducted in Lahore found that 85.5 percent of school pupils (aged 12 to 20 years) suffer from headache. 43.1 percent presented with mild headache, 46.6 percent presented with moderate headache, and 8.8 percent presented with severe headache. ${ }^{5}$ Patients who suffer from headaches daily are classified as having secondary or primary headaches, giant cell arteritis, malformation, vasculitis, and carotid dissection, pseudotumor cerebri, neoplasm, infection, subdural hematoma, and posttraumatic headache. ${ }^{6,7}$ Most of the headaches are physiologically benign and treatable in a family care practice environment. ${ }^{8}$ When the headache is a disorder itself, it is challenge to differentiate primary headache from the secondary headache, since primary headache requires no brain scans due to its nature, because there is no such disease condition that enables macroscopic changes in general. Who should patients undergo a scan if they have a headache? A scan, either magnetic resonance imaging (MRI) or computed tomography (CT-scan), is considered for patients who have headaches of secondary aetiology. Finally, how many possibly normal scans might society be willing to pay for in order to identify curable brain disease? ${ }^{9}$ How can you tell the difference between a primary and a secondary headache? Because no controlled trials to determine etiology of secondary headaches have been undertaken, this concern can only be explained clinically. We commonly believe in clinical settings that the red flags of headache must provoke an investigation for secondary headache. Identification of serious headache causes necessitates a systematic diagnostic technique to examination and history, as well as knowledge of a limited number of essential secondary headache diseases and referral criteria. ${ }^{10}$ Randomised controlled prospective trials involving brain scanning with CT-scan and MRI studied 9322 people with headache attending a primary care practise in the United States found 5869 patients with migraine..$^{9,12}$ Patients' demands for thorough and high-tech evaluations, as well as the growing practise of definitive 
medicine, appear to be speeding up the adoption of MRI in headache assessment. ${ }^{10}$ There is scarcity of the literature from our country about the spectrum of space occupying lesions of brain. Therefore, this study has been conducted to determine the space occupying lesions of brain, so policy could be devised to prevent these morbidities.

\section{MATERIAL AND METHODS}

This descriptive case-series study was conducted at department of Neurosurgery of Peoples University of Medical and Health Sciences, for Women Shaheed Benazirabad. Study duration was one year from July 2019 to June 2020. All the patients with space-occupying lesion of brain either of gender were included in the study. All the study subjects underwent computed tomography CT scan or MRI for the diagnosis. All the patients were assessed for causes of space-occupying lesion. Data was collected vis study proforma and analysis of the data was done by using SPSS version 20.

\section{RESULTS}

A total of 80 patients were selected to analyze the type of brain lesions and its causes. The mean age of the patients was 31.76 years. Out of all $34 \%$ were males and $66 \%$ were females with female to male ratio of 1.96:1. Table.1

Table. 1. Descriptive statistics of age and gender of the patients $=80$

\begin{tabular}{|c|c|c|}
\hline \multicolumn{2}{|c|}{ Variables } & Statistics \\
\hline \multicolumn{2}{|l|}{ Age (mean+SD) } & $31.76+17.80$ \\
\hline \multirow[b]{2}{*}{ Gender } & Male & $27(34.0 \%)$ \\
\hline & Female & $53(66.0 \%)$ \\
\hline
\end{tabular}

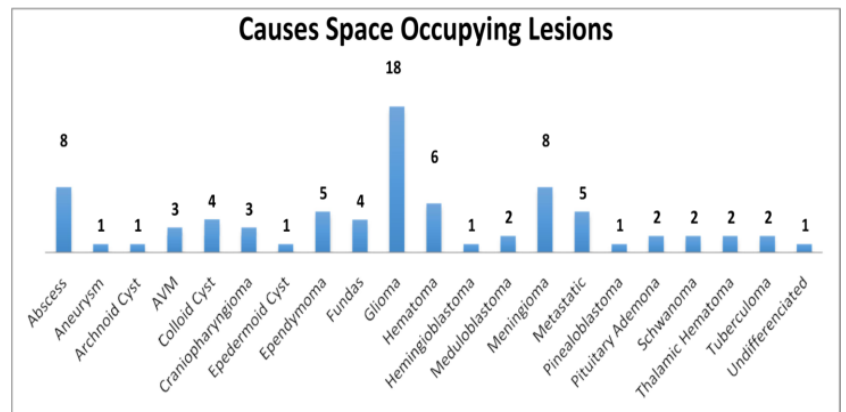

Fig: 1 Causes of space occupying lesions $n=80$

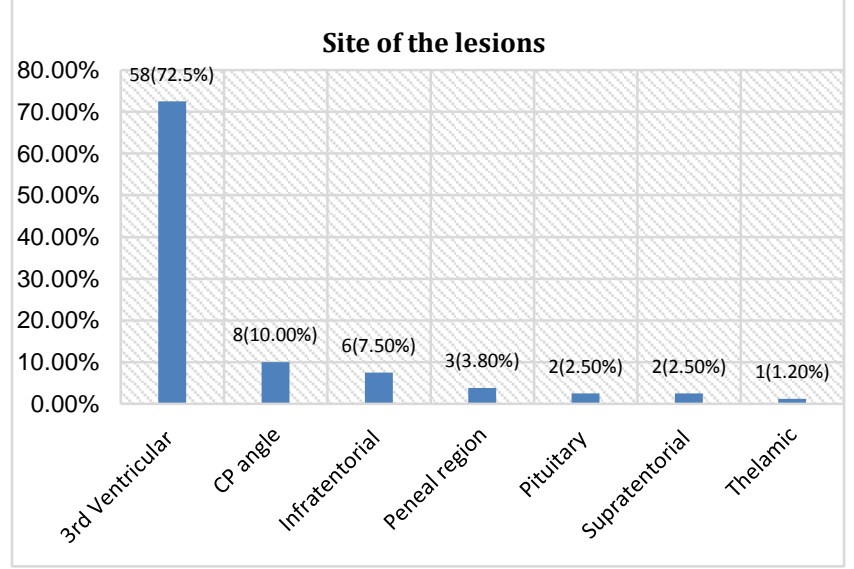

Fig 2: Site of the lesions $n=80$
Glioma was found among $23 \%$ of the patients which was highest among all type of lesion followed by abscess $10 \%$. Supratentorial was found in $73 \%$ of the patients which was highest among all site of lesion followed by third ventricular \& Infratentorial 10\% each as shown in table 2.

Stratification of space occupying lesion with respect to age was found to be significant and $\mathrm{P}(0.022)$

Stratification of space occupying lesion with respect to gender was found to be significant and $\mathrm{P}(0.014)$

Similarly for stratification of space occupying lesion with respect to site of lesion was found to be highly significant $P(0.014)$.

\section{DISCUSSION}

This study was conducted in a Neurosurgery unit of PMCH Nawabshah to detect the frequency of causes of space occupying lesions of brain diagnosis by diffusion weighted MRI. The observation of improvement in diagnosis is also confirmed by Aly IR, et al. ${ }^{19}$ They conducted a study on diffusion weight imaging in 150 patients of stroke and found that diagnosis was improved in $28 \%$ patients in whom the previous MRI was negative. In a study on 153 stroke patients scanned at a median of 2 days (range of 6 hours), recent infarcts were found more commonly on DWI (70\%) than on T2 weighted MRI (32\%) following stroke in all forms of severity of stroke. Within the first few hours after a stroke, DWI is shown to be successful in the majority of patients ${ }^{20}$. Another study conducted by Mullens Me, et $\mathrm{al}^{13}$, also confirms our observations. They conducted a study among 691 patients with stroke. They found that initial conventional MRI among stroke patients could find stroke finding among $58 \%$ patients while diffusion weighted MRI could detect stroke symptoms. Hence they found an improvement in diagnosis in $39 \%$ cases. Chan LL, et $\mathrm{al}^{21}$ studies the MRI and DWMRI findings in 22 consecutive patients with suspicion of stroke. They found that lesion visibility was highly accentuated on DWMRI with more than $75 \%$ lesions imaged at 4-48 hours after the initial symptoms. In our study, DWMI could detect brain lesion in $94.6 \%$ cases (hence revealed a sensitivity of $96.7 \%$ ) which is quite high and making it a more reliable investigation for detection of stroke in early time $\left(<6\right.$ houre) Kidwel, et al ${ }^{22}$ also had a similar report. They determined that DWMRI was sensitivities in $100 \%$ cases of stroke. Chen et $\mathrm{al}^{23}$, also detected that DWMRI obtained were most accurate investigation for detection of acute ischemic strokes. Thurnher $\mathrm{MM}$,et $\mathrm{al}^{24}$ determined that diffusion weighted imaging has a sensitivity of $99 \%$, specificity of $97 \%$ positive predictive value of $73 \%$, also predicts lesion volume and clinical severity and outcome.

In our study the mean age of the patients was 31.76 years. As compared with the study of Pickens $D^{14}$, the mean age of the patients was $33.8 \pm 15.6$ years, which is comparable with our study.

In our study there were $n=27$ (34\%) male patients and female $n=53(66 \%)$ patients. As compared with the study of Lansberg MG, Norbash AM et al $^{17}$, there were $68 \%$ male and $32 \%$ female patients, which is comparable with our study.

In our study Gioma was found to be $n=18$ (23\%) of the patients which was highest among all type of lesion followed by abscess $n=8(10 \%)$. As compared with the 
study of Berry I, Gigaud M, Manelfe $\mathrm{C}^{16}$,Gioma was $25 \%$ \& abscess was $15 \%$, which is comparable with our study.

In our study Supratentorial was found to be $\mathbf{5 8}(73 \%)$ of the patients which was highest among all site of lesion followed by third ventricular \& Infratentorial 8 (10\%) each. As compared with the study of Rosso C, Drier A, Lacroix $\mathrm{D}^{18}$, supratentorial was $71 \%$, ventricular \& Infratentorial was $7 \%$ and $9 \%$ respectively which is comparable with our study.

In present study, stratification of causes of brain lesions with respect to age was significant with chi- square (542.645) and $p$ value (0.022). As compared with the study of Bui JD, Buckley DL, et al ${ }^{15}$ with chi-square (530.66) and $p$ value $(0.028)$ which is comparable with our study. In present study, stratification of causes of brain lesions with respect to gender was significant with chi-square (36.465) and $p$ value (0.014). As compared with the study of Berry I, Gigaud M, Manelfe $\mathrm{C}^{16}$ with chi-square (32.36) and $p$ value (0.018) which is comparable with our study. In present study, stratification of causes of brain lesions with respect to site was significant with chi- square (542.645) and $p$ value (0.022). As compared with the study of Rosso $C$, Drier $A$, Lacroix $D^{18}$ with chi-square (530.66) and $p$ value $(0.028)$ which is comparable with ourstudy.

\section{CONCLUSION}

The increased prevalence of infectious lesions can be linked to our population's low socioeconomic level and inadequate hygienic conditions. The rate of metastasis was found to be lower than previously reported. This might be attributed to cases not being referred following a metastatic lesion has been diagnosed. For early detection of brain tumours, advanced diagnostic equipment such as $\mathrm{CT}$ scans and $\mathrm{MRI}$ are desirable.

\section{REFERENCE}

1. Donnan GA, Fisher M, Macleod M, Davis SM. Stroke Lancet 2008; 371:16121623.

2. Smith WS, English JD, Johnston SC. Cerebrovascular diseases I: Fauci AS, Braunwald E, Kasper DL, Houser SL,Longo DL, , Jameson $\mathrm{JL}$, LoscalzJ. editors Harrisons Principles of Internal Medicine, 17th ed. NewYork: McGRaw Hill2008;2513-2135.

3. Feigin VL, Lawes CM, Bennett DA, Barker-Collo SL, Parag V. Worldwide stroke incidence and early case fatality reported in 56 population-based studies: a systematic review. Lancet Neurol 2009 8:355-369.

4. Clarke CRA. Neurological diseases in: Kumar P, Clark Meditors Kumar and Clark Clinical Medicine 6th ed. London: Elsevier 2005;1209-1219.

5. Lopez AD, Mathers CD, Ezzati M, Jamison DT, Murray CJ.Global and regional burden of disease and risk factors,2001: systematic analysis of population health data. Lancet 2006;367:1747-1757.

6. Khan SN, Vohra EA. Risk factors for stroke: a hospital based study Pak J Med Sci 2007; 23:17-22.

7. Wardlaw JM, Mielke O. Early signs of brain infarction at CT: observer reliability and outcome after thrombolytic treatment-systematic review. Radiology 2005;235:444-453.

8. Graham GD. Secondary stroke prevention: from guidelines to clinicalpractice. J Natl Med Assoc 2008;100:1125-1137.

9. Hacke W, Kaste M, Bluhmki E, Brozman M. Thrombolysis with alteplase 3 to 4.5 hours after acute ischemic stroke. N Engl J Med 2008;359:1317-1329.

10. Kurukalasuria LR, Govindarjan G, Sowers J. Stroke prevention in diabetes and obesity. Expert Reve Crdiovasc Ther 2006;4:487-502.

11. Khan NI, Naz L, Mushtaq S, Rukh L, Ali S, Hussain Z ischemic stroke; prevalence of modifiable risk factor in male and female patient in Pakistan. Pak J Pharma Sci 2009;22:62- 67.

12. Parnetti L, Caso V, Lanari A, Saggese E, Sabastianelli M,Tayabeti SK, et al. Stroke prevention and statin treatment. Clin Exp Hypertens 2006;28:335-344.78

13. Mullins ME, Schaefer PW, Sorenson AG, Halpem EF, Ay H, He J. CT and conventional and Diffusion-weighted MR imaging in acute stroke: study in 691 patients at presentation to the Emergency Department. Radiology 2002;224:353-360.

14. Pickens D. Magnetic resonance imaging. In: Handbook of Medical Imaging. Volume 1. Physics and Psychophysics. Beutel J, Kundel H, Van Metter R, Sonka M, eds. Bellingham, Washington: SPIE Press 2000;414-415.

15. Bui JD, Buckley DL, Phillips MI, Blackband SJ. Nuclear magnetic resonance imaging measurements of water diffusion in the perfused hippocampal slice during N-methyl- Daspartate- induced excitotoxicity. Neuroscience 1999;93:487-490.

16. Berry I, Gigaud M, Manelfe C. Experimental focal cerebral ischaemia assessed with IVIM*- MRI in the acute phase at 0.5 tesla. Neuroradiology 1992;34:135-140

17. Lansberg MG, Norbash AM, Marks MP, Tong DC, Moseley ME Albers GW. Advantages of adding diffusion-weighted magnetic resonance imaging to conventional magnetic resonance imaging for evaluating acute stroke. Arch Neurol 2000;57:1311-1316.

18. Rosso C, Drier A, Lacroix D. Diffusion-weighted MRI in acute stroke within the first six hours. 1.5 or 3.0 Tesla? Neurology 2010;1-8. In press.

19. Aly IR, Allah HMS, Mahmood DH, El-Serafy M. Role of diffusion weighted MRI in early detection of ischemic cerebrovascular stroke. Bull Alex FAc Med 2008;44:677-691.91

20. Keir SL, Wardlaw JM, Bastin ME, Dennis MS. In which patients is diffusion weighted magnetic resonance imaging most useful in routine stroke care? J Neuroimaging 2004;14:18- 122.

21. Chan LL, Khoo BK, Thng CH, Lim WEH, Tay KH, Tan EK. Diffusion weighted MR imaging in Acute stroke: the SGH experience. Singapore Med J2002;43:118-123.

22. Kidwell CS, Saver JL, Mattiello J. Thrombolytic reversal of acute human cerebral ischemic injury shown by diffusion / perfusion magnetic resonance imaging. Ann Neurol 2000;47:462- 469.

23. Chen PE, Simon JE, HII MD. Acute ischemic stroke accuracy of diffusion weighted MR Imaging effects of $p$ value and cerebrospinal fluid suppression. Radiology 2006;238:232-239.

24. Thurnher MM,Castillo M. Imaging in stroke. Eur Radiol 2005;15:408415. 